\title{
REPAC information system
}

\author{
M. Cataldi, D. Ganapini, I. Travaglini
}

\begin{abstract}
In Italy, monitoring presences in the building site represents an important problem for technical and organising aspects and at the same time from the economical and administrative point of view. The existance of a social clause concerning the respect of the terms of the national contract signed by trade unions in the contracts of public works; the fragmentation of the productive cycle and of operators; the responsabilities and the present behaviours of the professionals charged with the management of works, of firms and of purchasers; incited to study and to test an integrated system for the treatment of data at a regional level, strictly connected with the data bank of the observatory of public works.
\end{abstract}

Index Terms-Building Industrial District, Monitoring, Public Works, Social Responsability.

\section{INTRODUCTION}

REPAC (REgistratore delle Presenze Autorizzate nei Cantieri) is an electronic system for monitoring building sites and generally the temporary working places distributed all over the country. The system is particularly used for identifying and registering the entrances and the permanences of all authorized workers in the building site.

The software and the procedures of the REPAC information system management allow to:

- control building sites at real time (and in particular sites of public works) in order to permit to all citizens who are interested in it to have a remote view of signs of the building site by a website and an intuitive navigation system with a territorial graphic support;

- control at real time the activities in the building site with entrance reserved to authorized persons: purchasers (work managers and safety coordinators), vigilance bodies

This work was supported partly by Regione Emilia-Romagna, the development of REPAC Information System was studied and tested thanks to AUSILIARE project (co-financed by "School. Professional Education, Employment. Pair Opportunities" Assessorship for the FSE initiative Objective 3, and is now in course of development and diffusion through INDICI project (co-financed by "Productive activities, Economical development. Telematic planning" Assessorship, with PRRIITT contribution).

Massimo Cataldi is manager of QUASAP, a department of the Regional Institute for Qualificazione e Sostenibilità del Costruire NUOVAQUASCO (e-mail: m.cataldi@quasap.it). He is responsible of REPAC programme.

Daniele Ganapini is manager of QUASCO, a department of the Regional Institute for Qualificazione e Sostenibilità del Costruire NUOVAQUASCO (e-mail: d.ganapini@quasco.it). He is the coordinator of AUSILIARE and INDICI projects.

Ilaria Travaglini, is a QUASAP consultant (corresponding author to provide information at phone number 0039-051-6334126).
(Direzione provinciale del Lavoro, Aziende USL, Prefetture), INAIL, INPS, Casse Edili and offices for the issue of a single document for compulsory contribution certification (Documento Unico per la Regolarità Contributiva - D.U.R.C.);

- verify efficiently, through a biomethrical identification, the identity, the entrance and the permanence of employees and authorized workers in the building site; then the possibility of an objection about presences in the site if not previously registered by REPAC;

- verify investigations on the building site and their single duration by the work director and the safety coordinator in phase of execution;

- survey perfectly the incidence of labour, also for specific workings. This evaluation could assume an average value if reference supposing that the survey includes a big number of homogeneous building sites.

The REPAC information system can be also developed to become the base on which other services could be realised for the management of building sites based on the activities of telesurveillance and/or documental exchange.

\section{SOURCES OF DATA OF THE INFORMATION SYSTEM}

REPAC Information System acquires its data from two sources:

- from institutional systems for monitoring public contracts and particularly, as far as Regione Emilia-Romagna is concerned, from SITAR, Sistema Informativo Telematico Appalti Regionale of Regione EmiliaRomagna which collects updated information about public work contracts in the phases of: programming, project-financing notice, announcement of tender, adjudication, start of works, states of progress and variants, conclusion of works, static test and technical and administrative test, in addition to information about contracts of supplyings and services;

- from devices of controlling identities and entrances installed in the building sites. The selected and adapted device is a digital electronic instrument for data transmission created for the identification of presences of authorized employees in the public work sites and for the remote transmission of data to the database installed on a server. This device, produced and adapted by SIRIO firm and requested by NUOVAQUASCO, has been conformed to its effectiveness according to specific environmental conditions of building sites. In particular 
every installed REPAC device allows:

- the control of identities of authorized entrances to the site based on the comparison of biomethrical data of fingerprint and registration. By a previous registration of persons, detailed information of the possible firms they work for could be known;

- registration of date and time of entrance of every identified employee;

- registration of date and time of exit of every identified employee;

- registration of date and time of every successful operation executed on REPAC (matriculation, qualification, cancellation of employees);

- remote transmission of data pointed out through a connection with PSTN modem to the server, in safe modality ${ }^{1}$;

- saving data into safety memories in order to recover them in case of operation problems and/or tampering of the device;

- absolute forbidden access to biomethrical data which are used by the device to verify the identities of persons.

This device has been constructed with physical features suitable to support the specific environment of the building site.

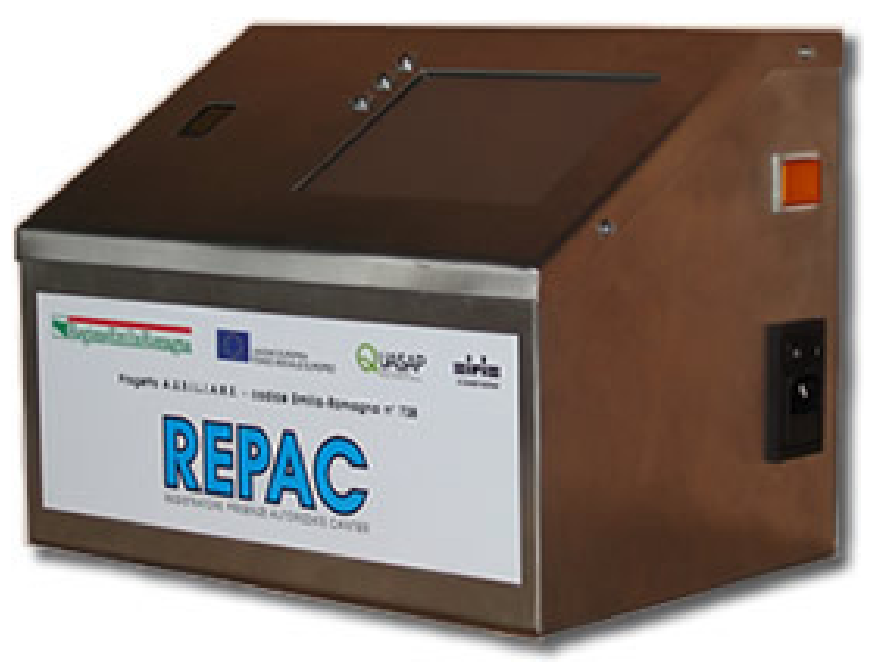

\section{BUILDING SITES INVOLVED IN REPAC TEST}

Building sites and Public Administrations which agreed to the test are:

ACER in Modena - Construction works of a building with 18 ERP lodgings in "S. Martino" PEEP, lot $n r .3 B$ in

1 The test manager (QUASAP Department) makes connections to REPAC device at programmed intervals, and in any time QUASAP thinks it would be necessary. Data will be transferred to management database and through the website, with specific procedures, they can be consulted with different modalities by the respective authorized users.
Campogalliano municipality;

INPS Direzione Regionale Emilia-Romagna - Remaking works of waste-pipes in two installations and secondary works at INPS provincial seat in Ferrara;

Province of Bologna - Remaking works of electric and special installations at Polo tecnico "Pacinotti Piercrescenzi" in Bologna - 2nd intervention;

Province of Rimini - Works of realization of a gymnasium at I.P.S.S.A.R. "Savioli" in Riccione.

In the building sites in Bologna and Ferrara, the test of REPAC devices started with the assignment of works to the purchaser, which took place respectively on July $1^{\text {st }}, 2004$ and on September $1^{\text {st }}, 2004$.

In Campogalliano REPAC was installed on September $23^{\text {rd }}$, 2004, about twenty days after the real start of works, but immediately afterwards the activities has been interrupted and then the use of REPAC is actually suspended.

In the building site in Rimini, because of delays in the accomplishment of procedures of tender for the assignment of works, as regards the expected programme, works have not started yet.. The installation of REPAC is expected to be done in autumn.

The most important administrative element of this agreement was the introduction, into the documents of the contract, of a clause about duties of purchasers to use and preserve the device. The study of this clause occurred for the directions given by the European Union (see bibliographical references).

\section{INSTRUCTIONS FOR THE USE OF REPAC DEVICE IN THE BUILDING SITE}

After REPAC installation and qualifying the Director of Works as its administrator, the Director of Works registers the Director of the Site and the Safety Coordinator in phase of Execution on the REPAC device, before these employees enter the building site for the first time. The registration of the Safety Coordinator can be done by the Director of the Site, who can manage REPAC even if from a lower position in relation to the Director of Works.

The Director of the Site registers on REPAC the Substitute of the Director of the Site (if any) before he enter the site for the first time.

The Director of Works, the Director of the Site (or his Substitute) and the Safety Coordinator in phase of Execution must always make themselves identified by REPAC before all entrances and exits from the building site.

The Director of the Site (or his Substitute) registers on REPAC employees of the purchaser, the subpurchaser, the subcontractor, before all entrances and exits from the building site.

The Director of the Site (or his Substitute) could do on REPAC the operation of forced exit of an employee entered in the site, if he wasn't able to do it because of an accident or another reason. These forced exits must be justified on a special register. (however REPAC documents all forced exits). 
The Director of Works could do the operation of Cancellation of an employee on REPAC, if in the building site it seems necessary the substitution of the Director of the Site or of the Safety Coordinator in phase of Execution.

The substitution of the Director of Works could be done only by the service manager.

\section{MODALITIES OF ACCESS TO DATA BY PRIVILEGED USERS OF THE INFORMATION SYSTEM}

Each user with a privileged modality (PROFILE) of access to REPAC information system, before entering he must have himself registered to the service.

The registration will occur by filling-in a special form prepared on the website. The completely filled-in form will be acquired by the information system by web.

Successively, through a self-certification sent by fax by persons willing to be qualified, after a control, the service manager will proceed, to validate the respective accounts allowing them the access to their private information. During the qualification, the service manager will communicate the successful result.

After being qualified, the users of the information system with a privileged profile could enter their private area and consult their pertaining data.

In particular, the representative of every purchaser could have access only to data of the building sites of the purchaser's competence; every Director of Works could have access to data of the site/sites where he works only; the employees charged to issue the D.U.R.C. document (Sportello Unico created by D.Lgs. 266/2002 e degli Organi di vigilanza) can have access to all building sites on the territory of their competence.

\section{Test REsults}

By the test the following main results have been achieved: Hardware and software conformity and configuration of the device of biomethrical identification of people, setting up the REPAC device which permits the biomethrical identification of employees in the building sites distinguishing them for their individual user's profile, the registration of the entrances and the exits of all authorized employees, the remote data transfer by modem using a telephone-line or a GSM card.

Realization of the database prototype of REPAC information system collecting data from the building sites which are monitored by SITAR and from REPAC device.

Realization of the prototype of the website for pointing out building sites and their signs on a map;

Realization of the prototype of the website for the access by various privileged profiles of authorized users to consult information about building sites monitored by REPAC device.

\section{CONCLUSIONS}

The prototype of REPAC information system is sufficiently developed in order to be already used for the realization of some services:

Realization of a service for consulting by web the signs of public work sites in a determinate territory:

The users of this service are all citizens who would be informed at real time about work costs, start, duration, eventual suspensions and extensions, expected conclusion, purchaser firms and subcontractor, professionals and eventual suspensions and extensions of started public works.

Potential distributors: Region, Provinces, Municipalities.

Realization of a monitoring service of contracts of a stated administration.

As addressees of the service, administrations realising contracts and willing to have a progress synthesis of all building sites and a precise monitoring of the activities of employed professionals, of purchasers, subpurchasers and subsupplying firms operating in the sites and of employed workers.

Realization of a monitoring service of workers employed by firms in their building sites.

As addressees of the service, firms having a lot of building sites distributed all over the territory and willing to have an updated monitoring of their own employees and of the presence of subcontracting and subsupplying firms in the building sites.

Realization of a precise control service of contribution and insurance reliability of firms.

Addressed to firms willing to certify their absolute contribution and insurance reliability of employees in their building sites also in case of incentives and/or benefits assigned by a third party.

Evolutions of REPAC Information System are numerous and must all be developed, mainly in two activity directions:

The first one connected with telesurveillance, by which the device can become extremely efficient even without supervisory control actions.

The second one connected with the documental exchange by which interactions between the building site and the seats of firms, the seats of purchasing administrations, the seats of insurance and security institutes, the seats of building organizations and the sportello unico INPS - INAIL - CASSE EDILI could be expected. 